\title{
Low-inspired oxygen condition on cardiorespiratory, metabolic functions and exercise performance.
}

\author{
Chaiyakul S*, Chaunchaiyakul $\mathbf{R}$ \\ College of Sports Science and Technology, Mahidol University, Thailand
}

\begin{abstract}
To investigate changes in physiologic and metabolic functions from exercise under acute low-inspired oxygen condition. Thirty three male-football players progressively exercised at submaximal workloads of 60, 90, 120 and 150 watts on cycle ergometer under two randomized conditions of normobarichypoxia $\left(15 \% \mathrm{O}_{2}, \mathrm{HYP}\right)$ and normoxia $\left(21 \% \mathrm{O}_{2}\right.$, NOR). Exercise performance, cardiorespiratory and metabolic profiles were continuously monitored. No significant differences between groups on cardiac variables, with the exception of significantly higher heart rate (HR) in HYP at all workloads. Respiratory variables, after 90 watts, showed remarkable increased in HYP $(p<0.05)$. At highest intensity, HYP condition showed significantly reductions of end diastolic volume (EDV), end systolic volume (ESV) and ejection fraction (EF) with significantly higher respiratory rate $(\mathrm{RR})$, tidal volume $(\mathrm{VT})$, pulmonary ventilation $\left(\mathrm{V}_{\mathrm{E}}\right)$ and carbon dioxide production $\left(\mathrm{VCO}_{2}\right)(\mathbf{p}<0.05)$. Exercise under hypoxic condition limits cardiac function but not for respiratory system. The parallel rising in $\mathrm{VO}_{2}$ and $\mathrm{VCO}_{2}$ at higher submaximal workload reflects to the limitation in $\mathrm{VO}_{2}$ with further increasing in $\mathrm{VCO}_{2}$ at maximal intensity. These will reduce physical performance. Awareness of cardiac deteriorations should be concerned for those who have to work hard under low $\mathrm{O}_{2}$ conditions.
\end{abstract}

Keywords: Exercise, Cardiac output, Hypoxia, Ventilation.

Accepted on February 11, 2019

\section{Introduction}

Exercises are being used as part of health promotion and prevention in many countries [1]. Various exercise applications had been intervened to hasten health improvement for both normal and handicapped adults [2-5]. Among various interventions, hypoxic exposure becomes more popular for its major hematological and physiological changes [6]. On the other hands, acute hypoxia was reported to decline exercise performance and oxygen utilization even at moderate altitude $\left(\mathrm{FIO}_{2} 12-15 \%\right)[7,8]$. This will affect the integrated function of cardiovascular and respiratory systems to deliver oxygen to tissues, which may impair metabolic processes [7]. Respiratory functions, the other system in concern, has been known to play primary roles to acute low-inspired oxygen via activation of peripheral chemoreceptor sensitivity [9], resulting in sudden increases of tidal volume, respiratory rate and minute ventilation to compensate for gas exchange at the lung. However, this readjustment diminished after 1 or 2 days of continuous hypoxic exposure [10].

Acute exposure to moderate hypoxia may alter most of cardiovascular functions at rest and even during exercise. Effects of acute exercise under hypoxia on cardiovascular function remain unclear. A study using echocardiographic finding shows mild LV diastolic dysfunction in young healthy mountaineers [11]. Other studies reported the compensations of the reduction in systemic vascular resistance at rest under acute hypoxia [12] and increase in heart rate and cardiac output [13]. The other studies disagreed with the controversial results about the effect of acute low-inspired oxygen condition on cardiac functions in which stroke volume (SV), cardiac output (CO) and left ventricular functions were all deteriorated during physical activity $[8,11,14]$. Whereas some studies reported unchanged in the above cardiac variables [15,16]. With limitations on methods and scattered variables of cardiac function from numbers of previous researches, the present study will use the cardiac impedance method to continuously monitor HR, SV, EDV, ESV, \%EF and SVR at rest and during exercise. Moreover, telemetry gas analyzer allows this study to collect data on metabolic and respiratory changes at the same time. Therefore an objective of this study is to investigate the cardiovascular responses and concomitant changes of respiratory and metabolic during exercise under normobaric hypoxic condition in well trained subjects. We hypothesized that acute hypoxic exposure in combination with physical exercise might deteriorate on cardiovascular, respiratory systems and metabolic function for those hypoxic-naïve subjects. 


\section{Methods}

\section{Subjects}

Male football players, age ranges between 18-22 years from Institute of Physical Education and Sports School, voluntarily joined in this cross-over designed study. They were currently participated with football training $>1$ hour/day, over than 3 days/week for $>3$ years. Following physical examination, medical screening and questionnaires on health-related physical activity history were conducted. Informed consent forms were signed prior to the test. On the day prior to the test, subjects were asked to refrain from other heavy exercise or sports, had regular meals with ad libitum for water and slept more than 8 hours. This study was approved by the Human Research Committee of Ethical Reinforcement for Human Research, Mahidol University, Thailand (MU-CIRB 2015/075 1905).

\section{Low-inspired oxygen (Hypoxic) condition}

Both normobaric-hypoxic ( $\mathrm{HYP}, \mathrm{FIO}_{2}=0.15$, approximately equivalent to 2500-3000 metre altitude) and normobaricnormoxic (NOR, $\mathrm{FIO}_{2}=0.21$ ) conditions were conducted within the hypoxic chamber (Altitude ${ }^{\circledR}$, Australia). Humidity and temperature were monitored throughout the experiment.

\section{Physiological measurement}

Cardiorespiratory and metabolic functions at rest and during exercises were continuously monitored using an impedance cardiography method (PhysioFlow ${ }^{\circledR}$ Enduro, Manatec Biomedical, Macheren, France) and telemetry gas analyser (Oxycon Mobile ${ }^{\circledR}$, CareFusion, Hoechberg, Germany). Variables, derived from these non-invasive methods including heart rate (HR) stroke volume (SV), cardiac output (CO), end diastolic volume (EDV), end systolic volume (ESV), systemic vascular resistance (SVR), ejection fraction $(\mathrm{EF})$, respiratory rate $(\mathrm{RR})$, tidal volume (VT), pulmonary ventilation (VE), oxygen consumption $\left(\mathrm{VO}_{2}\right)$, carbon dioxide production $\left(\mathrm{VCO}_{2}\right)$ and respiratory exchange ratio (RER), were continuously recorded. In addition, oxygen saturation $\left(\mathrm{SpO}_{2}\right)$ values were verified using fingertip pulse oximeter (Nonin GO2 Achieve ${ }^{\circledR}$, Minnesota, USA).

\section{Exercise protocol}

Two separated progressive exercise tests were randomly conducted, at least 1 week apart, either under normobaricnormoxic (NOR) or normobaric-hypoxic (HYP) condition on Monark cycle ergometer. After resting data collection, subjects started exercise with $60 \mathrm{rpm}$ at 60 watts for 3 minutes then workloads were gradually increased at 30 watts per 3 minutes. All physiologic variables were compared at rest (initial workload of 0 watts) and during progressive exercise in parallel with subjective evaluation (rating of perceived exertion, RPE). Each subject was verbally encouraged to exercise up to his maximum effort. Termination criteria was determined according to two of the followings: subject approached his peak oxygen consumption, age-predicted maximum heart rate, RPE at above 18 or voluntarily stopped due to exhaustion [17].

\section{Statistical analysis}

The values were expressed as mean and SEM, otherwise will be stated. The Shapiro-Wilk test was used to examine the normality of data distribution. Data obtained from progressive workload testing were compared using two-way ANOVA. Data at maximal exercise were compared using pair t-test. Significant level was set at $\mathrm{p}<0.05$.

\section{Results}

\section{Subjects characteristics}

Their training experience in football was about 5.5-6.3 years. Age and body mass index (BMI) of the subjects were $19.04 \pm$ 0.45 years and $19.76 \pm 1.98 \mathrm{~kg} / \mathrm{m}^{2}$ (Mean $\pm \mathrm{SD}$ ), respectively. Resting values of HR, systolic/diastolic blood pressure and $\mathrm{SpO}_{2} \%$ were $64.32 \pm 2.14$ beats $/ \mathrm{min}, 112 \pm 3.56 / 76.91 \pm 3.52$ $\mathrm{mmHg}$ and $99.51 \pm 0.22 \%$, respectively. RPE changed from 8 at initial workload (60 watts) and then progressively increased with higher workloads. There were no significant differences of RPE between two groups up to the maximum workload of 210 watts with 18-20 RPE ranges (Figure 1A). All subjects could finish up to 150 watts, however, numbers of subject who completed exercise at higher workload reduced (Figure 1B). At 180 watts, 2 subjects in NOR stopped exercise from volitional termination and approaching highest RPE, whereas 13 subjects in HYP terminated from volitional termination, approaching highest RPE and HRmax ( $n=1,10$ and 2 respectively). At 210 $\mathrm{w}$, another 6 subjects terminated exercise from highest RPE and approaching HRmax ( $\mathrm{n}=4$ and 2$)$ in NOR, whereas another 9 subjects in HYP terminated exercise with volitional termination, approaching highest RPE and $\mathrm{HR}_{\max }(\mathrm{n}=1,5$ and 3 respectively). Thus, the comparisons for all variables in the present study will be made from 60 up to 150 watts.

\section{Maximum exercise performance}

On average, maximum workload (estimated from workload beyond 150 watts) in HYP was lower than in NOR condition $(p<0.05)$. Compared between HYP and NOR at the averaged highest workload (Table 1), HYP showed significant reduction in most of hemodynamic variables $\left(\mathrm{SpO}_{2}, \mathrm{HR}, \mathrm{SV}, \mathrm{CO}, \mathrm{EDV}\right.$, ESV) $(p<0.05)$, with the significantly increased in most of respiratory variables $(R R$ and $V E)(p<0.05)$ and significant reduction in $\mathrm{VO}_{2}(\mathrm{p}<0.05)$ and increased in $\mathrm{VCO}_{2}$ and $\mathrm{RER}$ $(\mathrm{p}<0.05)$.

Table 1. Comparisons on responses of cardiac, respiratory and metabolic functions at averaged maximum exercise intensity under normobaric-normoxic (NOR) and low-inspired oxygen (HYP) conditions.

\begin{tabular}{llll}
\hline Variables & NOR & HYP & \%Difference \\
\hline Cardiac variables: & &
\end{tabular}




\begin{tabular}{llll}
\hline $\mathrm{SpO}_{2}(\%)$ & $99.76 \pm 0.23$ & $82.24 \pm 2.31^{\mathrm{a}}$ & $-17.45 \pm 3.14$ \\
\hline Systolic BP $(\mathrm{mmHg})$ & $202.67 \pm 5.21$ & $204.56 \pm 3.31$ & $+1.23 \pm 0.15$ \\
\hline Diastolic BP $(\mathrm{mmHg})$ & $78.41 \pm 3.72$ & $80.90 \pm 4.73$ & $+1.56 \pm 0.21$ \\
\hline $\mathrm{HR}(\mathrm{beats} / \mathrm{min})$ & $185 \pm 2.61$ & $175 \pm 2.27^{\mathrm{a}}$ & $-4.35 \pm 2.13$ \\
\hline $\mathrm{SV}(\mathrm{ml})$ & $119.00 \pm 3.62$ & $106.00 \pm 3.71^{\mathrm{a}}$ & $-2.14 \pm 0.45$ \\
\hline $\mathrm{CO}(\mathrm{L} / \mathrm{min})$ & $22.59 \pm 0.78$ & $18.34 \pm 0.61^{\mathrm{a}}$ & $-18.07 \pm 1.46$ \\
\hline EDV $(\mathrm{ml})$ & $225.74 \pm 4.62$ & $209.18 \pm 5.04^{\mathrm{a}}$ & $-6.37 \pm 1.23$ \\
\hline ESV (ml) & $117.38 \pm 4.01$ & $105.48 \pm 3.16^{\mathrm{a}}$ & $-9.03 \pm 1.71$ \\
\hline EF (\%) & $68.14 \pm 3.59$ & $62.32 \pm 4.81$ & $-6.31 \pm 1.05$
\end{tabular}

data showed the intensity-dependent characteristics for both conditions. Among cardiac variables, only $\mathrm{HR}$ and SV remarkably increased from resting conditions $(p<0.05)$ since the first workload of 60 watts. Other variables of both groups showed increasing from resting condition at higher workloads $(\mathrm{p}<0.05)$ : EDV, ESV and CO at 90, 120 and 150 watts (HYP and NOR); EF at 120 watts (HYP) and 150 watts (HYP and NOR) and SVR at 120 and 150 watts (HYP and NOR). Comparisons between two conditions showed significantly higher HR in HYP than NOR at 60, 90 and 120 watts $(p<0.05)$; higher EDV, ESV and EF in NOR than HYP at 150 watts; higher SVR in NOR than HYP at 90, 120 and 150 watts $(\mathrm{p}<0.05)$.
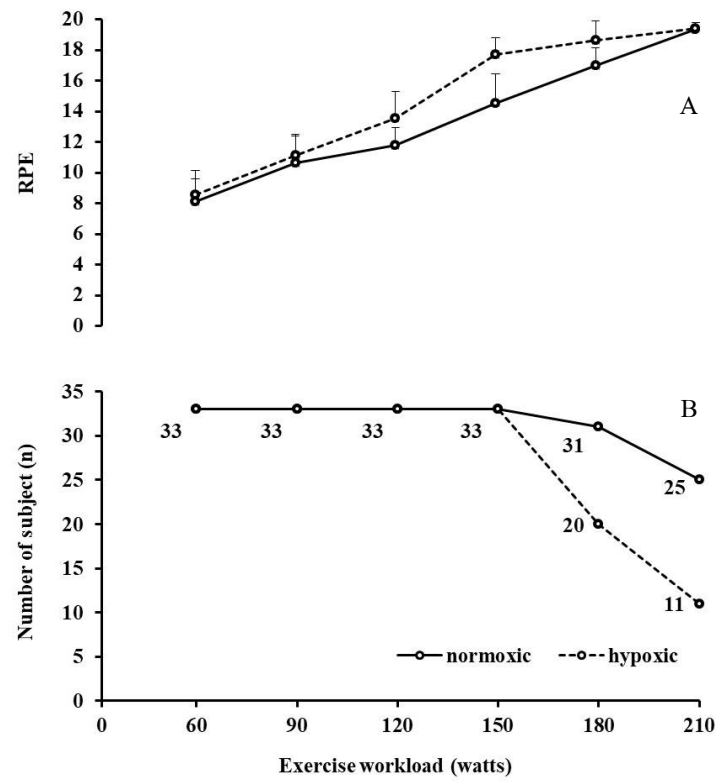

Respiratory variables:

\begin{tabular}{llll}
\hline RR (breaths $/$ min) & $38.76 \pm 2.90$ & $43.56 \pm 2.65^{\mathrm{a}}$ & $+14.32 \pm 2.49$ \\
\hline VT (L) & $1.82 \pm 0.14$ & $2.05 \pm 0.12$ & $+10.45 \pm 0.09$ \\
\hline VE (L/min) & $66.80 \pm 3.25$ & $80.45 \pm 3.56^{\mathrm{a}}$ & $+19.24 \pm 3.02$
\end{tabular}

Gas exchange variables:

\begin{tabular}{llll}
\hline$\dot{\mathrm{VO}} 2(\mathrm{ml} / \mathrm{kg} / \mathrm{min})$ & $45.75 \pm 2.65$ & $40.45 \pm 0.67^{\mathrm{a}}$ & $-11.84 \pm 1.26$ \\
\hline$\dot{\mathrm{V}} \mathrm{CO}_{2}(\mathrm{ml} / \mathrm{kg} / \mathrm{min})$ & $42.14 \pm 3.23$ & $49.34 \pm 2.56^{\mathrm{a}}$ & $+13.45 \pm 2.15$ \\
\hline $\mathrm{RER}$ & $1.12 \pm 0.43$ & $1.24 \pm 0.36^{\mathrm{a}}$ & $+8.51 \pm 0.11$ \\
\hline
\end{tabular}

Exercise performance
variable:

$\mathrm{WR}_{\max }$ (watts)

$198.56 \pm 3.14 \quad 184.60 \pm 2.12^{\mathrm{a}} \quad-9.05 \pm 1.16$

arepresents significantly different between two conditions. Abbreviations: $\mathrm{SpO}_{2}$ (oxygen saturation). HR: Heart Rate; SV: Stroke Volume; CO: Cardiac Output; EDV End Diastolic Volume; ESV: End Systolic Volume; EF: Ejection Fraction; RR Respiratory Rate; VT Tidal Volume; VE Miniute Ventilation; $\dot{V}_{2}$ : Oxygen Consumptionl $\mathrm{VCO}_{2}$ : Carbon Dioxide Production; RER: Respiratory Exchange Ratio; $W_{\text {max }}$ : Maximum Workload. \% differences were calculated from HYPNOR values.

\section{Cardiac functions during submaximal exercise}

There was no significant different of resting cardiac variables between NOR and HYP conditions (Table 2). During exercise,

Figure 1. Rate of perceived exertion (RPE, A) and numbers of subject $(n, B)$ who completed progressive exercise test up to highest workload in normoxic (solid line) and low-inspired oxygen (hypoxic) condition (dashed line). It is noted that numbers of subject completed above 150 watts declined.

Table 2. Cardiac responses during progressive exercises at submaximum workloads (60,90, 120, 150 watts) under normobaric-normoxic (NOR) and low-inspired oxygen (HYP) conditions.

\begin{tabular}{|c|c|c|c|c|c|c|}
\hline \multirow[t]{2}{*}{ Variables } & \multirow[t]{2}{*}{ Group } & \multirow[t]{2}{*}{ Resting } & \multicolumn{4}{|c|}{ Exercise workload (watts) } \\
\hline & & & 60 & 90 & 120 & 150 \\
\hline \multirow[t]{2}{*}{ HR (beats/min) } & NOR & $75 \pm 3.43$ & $110 \pm 3.55^{*}$ & $120 \pm 4.70^{\star \star * \star}$ & $148 \pm 5.14^{*, * \star}$ & $167 \pm 4.29^{\star \star * \star}$ \\
\hline & HYP & $85 \pm 2.16$ & $124 \pm 4.23^{\star}, \mathrm{a}$ & $131 \pm 3.08^{*}, \mathrm{a}$ & $160 \pm 4.18^{*, * \star, a}$ & $175 \pm 3.27^{\star, \star \star *}$ \\
\hline \multirow[t]{2}{*}{$\mathrm{SV}(\mathrm{ml})$} & NOR & $71.59 \pm 4.36$ & $82.19 \pm 4.82^{*}$ & $96.00 \pm 5.30^{*, * *}$ & $108.00 \pm 5.01^{*, * *}$ & $115.00 \pm 5.20^{*, * *}$ \\
\hline & HYP & $68.61 \pm 4.01$ & $79.27 \pm 3.70^{*}$ & $92.00 \pm 3.56^{*, * *}$ & $104.00 \pm 3.47^{*, * *}$ & $108.00 \pm 3.71^{*}$ \\
\hline \multirow[t]{2}{*}{ EDV (ml) } & NOR & $140.18 \pm 4.21$ & $142.18 \pm 3.78$ & $172.49 \pm 4.32^{*}$ & $184.32 \pm 5.41^{*}, * *$ & $198.14 \pm 4.38^{*, * *}$ \\
\hline & HYP & $137.05 \pm 5.46$ & $140.89 \pm 5.15$ & $163.74 \pm 4.47^{*}$ & $176.14 \pm 3.50^{*},{ }^{* *}$ & $181.71 \pm 5.14^{*}, \mathrm{a}$ \\
\hline \multirow[t]{2}{*}{ ESV (ml) } & NOR & $62.34 \pm 3.30$ & $64.52 \pm 4.560$ & $78.21 \pm 3.04^{*}$ & $85.32 \pm 3.84^{*}$ & $87.41 \pm 3.16^{*}$ \\
\hline & HYP & $57.46 \pm 3.74$ & $60.21 \pm 3.86$ & $74.83 \pm 3.51^{*}$ & $78.46 \pm 3.19^{*}$ & $65.37 \pm 3.06^{\star}, \mathrm{a}$ \\
\hline
\end{tabular}




\begin{tabular}{|c|c|c|c|c|c|c|}
\hline \multirow[t]{2}{*}{$\mathrm{CO}(\mathrm{L} / \mathrm{min})$} & NOR & $5.73 \pm 0.37$ & $6.80 \pm 0.55$ & $11.07 \pm 0.64^{*, * \star}$ & $14.70 \pm 0.65^{\star \star * *}$ & $17.37 \pm 0.78^{*, * *}$ \\
\hline & HYP & $7.27 \pm 0.36$ & $8.60 \pm 0.48$ & $13.42 \pm 0.59^{*, * *}$ & $16.45 \pm 0.64^{*, * *}$ & $18.84 \pm 0.61^{*}$ \\
\hline \multirow[t]{2}{*}{$\mathrm{EF}(\%)$} & NOR & $60.12 \pm 3.45$ & $62.35 \pm 4.56$ & $61.32 \pm 4.16$ & $65.38 \pm 3.96$ & $66.06 \pm 5.12^{*}$ \\
\hline & HYP & $59.42 \pm 4.56$ & $58.32 \pm 4.17$ & $56.48 \pm 5.19$ & $58.45 \pm 4.55 a$ & $61.14 \pm 3.81^{a}$ \\
\hline \multirow[t]{2}{*}{ SVR (dyne/cm ${ }^{5}$ ) } & NOR & $705.48 \pm 103.16$ & $1178.54 \pm 28.74$ & $1046.28 \pm 32.14$ & $903.18 \pm 0.46^{*}$ & $843.01 \pm 29.84^{*}$ \\
\hline & HYP & $645.51 \pm 78.94$ & $1021.08 \pm 30.46^{a}$ & $937.65 \pm 27.84^{a}$ & $746.82 \pm 8.55^{*},{ }^{* *}, \mathrm{a}$ & $674.81 \pm 24.81^{*}$ \\
\hline
\end{tabular}

"represents significantly different from the corresponding resting value; ${ }^{* *}$ significantly different from previous value of the same condition and; a significantly different between two conditions. Abbreviations: HR: Heart Rate; SV: Stroke Volume; CO: Cardiac Output; EDV: End Diastolic Volume; ESV: End Systolic Volume; EF: Ejection Fraction; SVR: Systemic Vascular Resistance.

\section{Respiratory function during submaximal exercise}

Respiratory variables also showed the intensity-dependent characteristics during exercise in both conditions (Table 3 ). In NOR and HYP conditions, RR, VT and VE remarkably increased $(p<0.05)$ from resting conditions since the first workload of 60 watts. At higher workloads from 90 up to 150 watts, HYP showed significantly higher RR $(\mathrm{p}<0.05)$, VT $(p<0.05)$ and VE $(p<0.05)$ than NOR group. Data on $\% \mathrm{SpO}_{2}$ revealed the unchanged in $\mathrm{SpO}_{2}$ in NOR but showed progressively diminished $(\mathrm{p}<0.05)$ in HYP at all workloads.

Table 3. Respiratory responses during progressive exercises at submaximum workloads (60, 90, 120, 150 watts) under normobaric-normoxic (NOR) and low-inspired oxygen (HYP) conditions.

\begin{tabular}{|c|c|c|c|c|c|c|}
\hline \multirow[t]{2}{*}{ Variables } & \multirow[t]{2}{*}{ Groups } & \multirow[t]{2}{*}{ Resting } & \multicolumn{4}{|c|}{ Exercise workload (watts) } \\
\hline & & & 60 & 90 & 120 & 150 \\
\hline \multirow[t]{2}{*}{ RR (breaths/min) } & NOR & $13.00 \pm 2.34$ & $17.7 \pm 3.21^{*}$ & $21.57 \pm 3.45^{*, * *}$ & $28.86 \pm 3.04^{*, * *}$ & $33 \pm 3.56^{* * * *}$ \\
\hline & HYP & $16.83 \pm 2.54$ & $23.45 \pm 3.17^{*}$ & $33.67 \pm 2.57^{*, * k}, a$ & $38.67 \pm 3.12^{*, * *}, \mathrm{a}$ & $42.56 \pm 2.65^{*, * *, a}$ \\
\hline \multirow[t]{2}{*}{ VT (L) } & NOR & $0.55 \pm 0.07$ & $1.10 \pm 0.10^{*}$ & $1.36 \pm 0.11^{*, * *}$ & $1.67 \pm 0.09^{*, * *}$ & $1.75 \pm 0.13^{*}$ \\
\hline & HYP & $0.79 \pm 0.10$ & $1.23 \pm 0.12^{*}$ & $1.62 \pm 0.14^{*, * *}, \mathrm{a}$ & $1.89 \pm 0.11^{*}, a$ & $2.05 \pm 0.12^{*}, a$ \\
\hline \multirow[t]{2}{*}{$\dot{\mathrm{V}} \mathrm{E}(\mathrm{L} / \mathrm{min})$} & NOR & $7.17 \pm 2.3$ & $21.47 \pm 3.11^{*}$ & $32.34 \pm 3.46^{*, * *}$ & $47.43 \pm 2.88^{*, * *}$ & $61.71 \pm 3.99^{*, * *}$ \\
\hline & HYP & $12.17 \pm 3.87$ & $29.33 \pm 2.88^{*}$ & $53.89 \pm 2.23^{*, * *}, a$ & $70.12 \pm 3.44^{*, * *}, a$ & $80.45 \pm 3.56^{\star}, a$ \\
\hline \multirow[t]{2}{*}{$\mathrm{SPO}_{2}(\%)$} & NOR & $99.74 \pm 0.01$ & $99.74 \pm 0.01$ & $99.62 \pm 0.02$ & $99.07 \pm 0.01$ & $98.48 \pm 0.02$ \\
\hline & HYP & $93.76 \pm 1.14$ & $93.76 \pm 1.14^{a}$ & $90.16 \pm 1.42^{\mathrm{a}}$ & $86.31 \pm 1.08^{*}, * *, a$ & $83.32 \pm 1.13^{*},{ }^{* *}, a$ \\
\hline
\end{tabular}

"represents significantly different from the corresponding resting value under the same condition; * ${ }^{* *}$ significantly different from previous value of the same condition and; ${ }^{a}$ significantly different between two conditions. Abbreviations: RR: Respiratory Rate; VT: Tidal Volume; VE: Pulmonary Ventilation; SpO 2 : Oxygen Saturation.

\section{Metabolic function during submaximal exercise}

Compared to resting values, NOR and HYP showed similar results with the progressive increased in $\mathrm{VO}_{2}$ and $\mathrm{VCO}_{2}$ $(\mathrm{p}<0.05)$ for all workloads (Table 4$)$. Comparisons between groups showed that HYP had higher $\mathrm{VO}_{2}$ than NOR $(\mathrm{p}<0.05)$ only at 120 watts; higher $\mathrm{VCO}_{2}$ than $\mathrm{NOR}$ at 90,120 and 150 watts $(p<0.05)$. In both groups, RER shifted from 0.8 at rest to $>1.0$ at 150 watts. Higher RER in HYP than NOR were also detected at 120 and 150 watts $(\mathrm{p}<0.05)$.

Table 4. Metabolic responses during progressive exercises at submaximum workloads (60, 90, 120, 150 watts) under normobaric-normoxic (NOR) and low-inspired oxygen (HYP) conditions.

\begin{tabular}{|c|c|c|c|c|c|c|}
\hline \multirow[b]{2}{*}{ Variables } & \multirow[b]{2}{*}{ Group } & \multirow[b]{2}{*}{ Resting } & \multicolumn{4}{|c|}{ Exercise at workload (watts) } \\
\hline & & & 60 & 90 & 120 & 150 \\
\hline $\mathrm{VO}_{2}$ & NOR & $6.51 \pm 1.45$ & $20.43 \pm 0.51^{*}$ & $24.46 \pm 1.28^{*, * *}$ & $29.71 \pm 1.97^{*, * *}$ & $38.23 \pm 2.27^{*, * *}$ \\
\hline$(\mathrm{ml} / \mathrm{kg} / \mathrm{min})$ & HYP & $6.80 \pm 2.52$ & $21.82 \pm 2.04^{*}$ & $27.72 \pm 1.44^{\star,, * *}$ & $34.57 \pm 1.40^{*, * *}, \mathrm{a}$ & $40.45 \pm 0.67^{*, * \star}$ \\
\hline $\mathrm{VCO}_{2}$ & NOR & $6.50 \pm 1.27$ & $18.6 \pm 0.64$ & $24.09 \pm 1.98^{*}$ & $30.9 \pm 1.64^{*, * *}$ & $36.95 \pm 2.4^{* * *}$ \\
\hline
\end{tabular}




\begin{tabular}{lllllll}
\hline$(\mathrm{ml} / \mathrm{kg} / \mathrm{min})$ & HYP & $5.61 \pm 2.22$ & $18.61 \pm 1.65$ & $29.28 \pm 1.16^{*, * *, a}$ & $35.32 \pm 1.27^{*, * *, a}$ & $43.71 \pm 1.73^{*, * *, a}$ \\
\hline \multirow{2}{*}{ RER } & NOR & $0.82 \pm 0.03$ & $0.85 \pm 0.02$ & $0.91 \pm 0.05^{*}$ & $0.93 \pm 0.03^{*}$ & $1.08 \pm 0.05^{*, * *}$ \\
\cline { 2 - 6 } & HYP & $0.87 \pm 0.05$ & $0.91 \pm 0.02$ & $0.99 \pm 0.04^{*}$ & $1.04 \pm 0.04^{*, a}$ & $1.19 \pm 0.05^{*, * *, a}$ \\
\hline
\end{tabular}

*represents significantly different from the corresponding resting value under the same condition; ${ }^{* *}$ significantly different from previous value of the same condition and; a significantly different between two conditions. Abbreviations: $\mathrm{VO}_{2}$ : Oxygen Consumption; $\mathrm{V} \mathrm{O}_{2}$ : Carbon Dioxide Production; RER: Respiratory Exchange Ratio.

\section{Discussion}

Three main physiologic functions of cardiac, respiratory and metabolic systems were concomitantly investigated during acute low-inspired oxygen exposure. Our result shows that acute exercise performance, of either maximum or submaximum workload, in hypoxic condition $\left(\mathrm{FIO}_{2} 15 \%\right)$ is suppressed while resting cardiorespiratory and metabolic functions remain unchanged. However, as graded exercise was conducted, the reductions in most of cardiorespiratory and metabolic functions appeared in low-inspired oxygen condition and only at higher workload. The reduction of maximum HR in parallel with oxygen utilization may possibly indicate the limitation of aerobic process which, in turn, diminished physical performance. As showed in the result, some of subjects cannot achieved the maximum exercise workload under hypoxic as compare to normoxic condition, it is indicating that aerobic exercise tolerance was reduced in those subjects. Concerning with differences of individual exercise tolerance caused by age, gender, oxygen carrying capacity, cardiorespiratory, muscle functions and level of physical fitness, and the experience of hypoxic exposure. This study recruited subject only those with no experience of hypoxia, never stayed or lived on altitude with same age, gender and physical fitness level. In addition, investigators allowed those subjects to familiar with hypoxic environment and screened out those with signs and symptoms.

Under hypoxic exercise, the compensations of cardiac outputs at a given submaximum workload were derived from the increasing in HR with the similar SV. While lower vasodilations were seen at all workloads, the suppression of EDV, ESV and EF were only observed at 150 watts. The simplification is that hypoxic condition induces higher heart rate at all workloads. The lower SVR at all workloads reflect that peripheral mechanism plays role on regulation of hemodynamic, however, there is still some impairment under hypoxic condition. This finding was accordance with the previous report from the study of Fukuda et al. they found that acute exercise under hypoxic condition significantly increase submaximal heart rate. However in that study, submaximal SV also shows a significantly reduce which was contrast to the present study [8]. At maximum workload, HR, SV, CO, EDV, ESV and SRV significantly decrease in hypoxic condition. It is indicating the limitation of cardiovascular compensation during acute hypoxic exercise. The higher sub maximum heart rate under hypoxic exercise is related to the sympathetic activation effect of hypoxia, which is evidence by elevated level of catecholamine and muscle sympathetic nerve activity evoked by a given workload [18-20]. In addition, it also related to parasympathetic withdrawal during submaximal workload under hypoxic exercise [21]. However, at maximal exercise under hypoxic condition, parasympathetic activation may gradually dominate sympathetic system. As evidenced by vagal-blockage, restoration of $\mathrm{HR}_{\max }$ in hypoxic to the same level as normoxic exercise was reported [22]. This limitation in $\mathrm{HR}_{\max }$ during hypoxic exposure in the present study may beneficially protect the induction of myocardial damages from too high oxygen demand during hypoxic exposure [23].

In the present study, stroke volume at a given submaximum workload was not difference between two conditions. Our finding was consistent with previously reported by Moon et al. that study found no significances differences in SV during submaximal exercise under hypoxic condition $\left(14.5 \% \quad \mathrm{FIO}_{2}\right)$ [13]. However, SV shows a decline in hypoxic condition at maximum workload. Mechanisms have been proposed for the reductions of maximum SV during hypoxic exposure are all related to either left or right ventricular function. One mechanism is the reduction of left ventricular diastolic function, from echocardiography-Doppler, demonstrated that acute normobaric-hypoxic $\left(\mathrm{FIO}_{2} 0.14\right)$ exposure reduced left ventricular diastolic function, whereas left ventricular systolic function was well preserved [24]. Another possible mechanism is the impairment of right ventricular function due to hypoxiainduced pulmonary vasoconstriction [25]. The reduction of SV found in this study was concomitant with low EDV and ESV but it was not related with EF. It is indicating of the limitation of cardiac function during acute hypoxic exercise. Theoretically, the reduction of EDV or preload resulted in lowering SV. The mechanism underlying the reduction in EDV during hypoxia might be a reduction in venous return does to impair muscle pumping [7]. Another possible explanation of the decreased EDV in hypoxia might be related to hypoxicinduced higher HR during exercise which shortened diastolic time interval and thus reduced EDV [26]. This study confirms the reduction of left ventricular diastolic function by reduction in EDV under hypoxic exposure. In addition, it is likely that decreasing in ESV is greater than decreasing in EDV during exercise under hypoxic condition despite the fact that SVR decreased in the greater extent than NOR condition. This vascular compensation still cannot compensate for central hemodynamic adjustment from the heart. Acute exercise under hypoxic condition significantly reduced SVR at sub-maximum workloads compared to same workload at normoxia. This possibly indicates the defects of regulatory mechanism via the periphery on vasodilation induced by hypoxic. Previous studies showed that acute hypoxic exposure was associated with compensatory vasodilatation in skeletal muscles $[27,28]$. This was explained via the releasing of higher amount of nitric 
oxide (NO) from endothelium as a result of hypoxic exposure [29-33].

At any exercise intensity, exercise under hypoxic condition induced greater respiratory responses in both rate and volume compared to normoxic condition. Under hypoxic condition, the partial pressure of oxygen was declined and resulting in the reduction of $\mathrm{SpO}_{2}$ which more progressive low when exercise was added as showed in the present study. Sympathetic and chemoreceptor activations concomitantly play important roles for respiratory drives during exercise under low-inspired oxygen level [34]. According to oxygen-hemoglobin dissociation curve, the reductions of $\mathrm{SpO}_{2} 93.76 \pm 1.14,90.16$ $\pm 1.42,86.31 \pm 1.08$ and $83.32 \pm 1.13 \%$ at $60,90,120$ and 150 watts in hypoxic condition were approximately equivalent to partial pressure of oxygen in arterial blood $\left(\mathrm{PaO}_{2}\right)$ of 60 $\mathrm{mmHg}$. Theoretically, it is indicated that the lower $\mathrm{PaO}_{2}$ of about $60 \mathrm{mmHg}$ will sensitize physiologic receptors in which peripheral chemoreceptors always responsible for reduction in $\mathrm{PaO}_{2}$, with immediate responses appear within few seconds. On the other hand, central chemoreceptor is activated by partial pressure of carbon dioxide in arterial blood $\left(\mathrm{PaCO}_{2}\right)$ in which $\mathrm{CO}_{2}$ from metabolism indirectly produces $\mathrm{H}^{+}$, the remarkable stimuli at higher center [35]. In addition blood lactate was also significantly increased during acute exercise under hypoxic condition [13]. Most of lactic acid dissociates into lactate anions and $\mathrm{H}^{+}$. Therefore, any increase in lactic acid and hence produced hydrogen ions can additionally stimulate central chemoreceptor. Exercise under hypoxic condition induces slightly higher metabolism for oxygen consumption but higher carbon dioxide production and RER at most of workloads. Results from RER reveal that there is, likely, metabolic shifting toward more anaerobic processes.

\section{Conclusion}

The decline in maximum performance under hypoxic condition is due to the reductions in most of cardiac variables and limitation in oxygen consumption. Despite the fact that respiratory adjustments are achieved, this compensation seems unlikely to facilitate maximum performance. Cardiorespiratory and metabolic responses are intensity dependent for both NOR and HYP conditions, however, limitations of cardiac function appeared in HYP at high workload. On the other hand, HYP induces greater respiratory compensation. Limitation of oxygen consumption appeared earlier under HYP whereas higher carbon dioxide productions remain at higher workloads. RER at high workload reflects the more possible involvement of anaerobic process.

\section{Acknowledgement}

We acknowledge the Sports Authority of Thailand (SAT) Regional 2 for providing Hypoxic chamber. We are grateful to coach and football players of Institute of Physical Education and Supanburi Sports School.

\section{Conflict of Interest}

No conflict of interest.

\section{References}

1. Scarapicchia TMF, Amireault S, Faulkner G, Sabiston CM. Social support and physical activity participation among healthy adults: a systematic review of prospective studies. Int Rev Sport Exerc Psychol 2016; 10: 50-83.

2. McKay HA, Macdonald H, Reed KE, Khan KM. Exercise interventions for health: time to focus on dimensions, delivery, and dollars. Br J Sports Med 2003; 37: 98-99.

3. OBrien TD, Noyes J, Spencer LH, Kubis HP, Hastings RP, Whitaker R. Systematic review of physical activity and exercise interventions to improve health, fitness and wellbeing of children and young people who use wheelchairs. BMJ Open Sport Exerc Med 2016.

4. Park HY, Lim K. Effects of hypoxic training versus normoxic training on exercise performance in competitive swimmers. J Sports Sci Med 2017; 16: 480-488.

5. Meender AG, Zalpour C, Piekartz HV, Hall TM, Paelke V. The Efficacy of electronic health-supported home exercise interventions for patients with osteoarthritis of the knee: systematic review. J Med Internet Res 2018; 20: 152.

6. Lumb AB. Nunns Applied respiratory physiology (7th Edn.). Elsevier 2010.

7. Peltonen JE, Tikkanen HO, Rusko HK. Cardiorespiratory responses to exercise in acute hypoxia, hyperoxia and normoxia. Eur J Appl Physiol 2001; 85: 82-88.

8. Fukuda T, Maegawa T, Marsumoto A. Effects of acute hypoxia at moderate altitude on stroke volume and cardiac output during exercise. Int Heart 2010; 51: 170-175.

9. Albert TJ, Swenson ER. Peripheral chemoreceptor responsiveness and hypoxic pulmonary vasoconstriction in humans. High Alt Med Biol 2014; 15: 15-20.

10. Garcia N, Hopkins SR, Powell FL. Intermittent vs continuous hypoxia: effects on ventilation and erythropoiesis in humans. Wilderness Environ Med 2000; 11: 172-179.

11. Allemann Y, Rotter M, Hutter D. Impact of acute hypoxic pulmonary hypertension on LV diastolic function in healthy mountaineers at high altitude. Am J Physiol Heart Circ Physiol 2004; 286: 856-862.

12. Wagner PD. Reduce maximal cardiac output at altitude mechanism and significance. Respir Physiol 2000; 120: $1-11$.

13. Moon HW, Sunoo S, Park HY, Lee DJ, Nam SS. Effects of various acute hypoxic conditions on metabolic parameters and cardiac function during exercise and recovery. SpringerPlus 2016; 5: 1294.

14. Kjaergaard J, Snyder EM, Hassager C, Olson TP, Oh JK, Johnson BD. The effect of $18 \mathrm{~h}$ of simulated high altitude on left ventricular function. Eur J Appl Physiol 2006; 98: 411-418.

15. Siebenmann C, Lundby C. Regulation of cardiac output in hypoxia. Scand J Med Sci Sports 2015; 25: 53-59. 
16. Boos CJ, OHara JP, Mellor A. A four-way comparison of cardiac function with normobaric normoxia, normobaric hypoxia, hypobaric hypoxia and genuine high altitude. PLoS One 2016; 11: e0152868.

17. Hamlin MJ, Draper N, Blackwell G, Shearman JP, Kimber NE. Determination of maximal oxygen uptake using the bruce or a novel athlete-led protocol in a mixed population. J Hum Kinet 2012; 31: 97-104.

18. Adamos T, Papanikolaou Z, Voutselas V, Soulas D. Effects of hypoxia on interval moderate exercise. $\mathrm{Zj}$ zbiol Exerc 2008; 4: 1-16.

19. Hainsworth R, Drinkhill MJ. Cardiovascular adjustments for life at high altitude. Respir Physiol Neurobiol 2007; 158: 204-211.

20. Katayama K, Ishida K, Iwamoto E, Iemitsu M, Koike T, Saito M. Hypoxia augments muscle sympathetic neural response to leg cycling. Am J Physiol Regul Integr Comp Physiol 2011; 301: 456-464.

21. Lundby C, Araoz M, van Hall G. Peak heart rate decreases with increasing severity of acute hypoxia. High Alt Med Biol 2001; 2: 369-376.

22. Hamilton AL, Brooks S, Willium C. Physiological responses to maximum intermittent exercise: differences between endurance-trained runner and game player. J Sports Sci 1991; 94: 371-382.

23. Hartley LH, Vogel JA, Cruz JC. Reduction of maximal exercise heart rate at altitude and its reversal with atropine. J Appl Physiol 1974; 36: 362-365.

24. Koller EA, Drechsel S, Hess T, Macherel P, Boutellier U. Effects of atropine and propranolol on the respiratory, circulatory, and ECG responses to high altitude in man. Eur J Appl Physiol Occup Physiol 1988; 57: 163-172.

25. Kullmer T, Katowa T, Kronenberger H. Experimental acute hypoxia in healthy subjects: evaluation of systolic and diastolic function of the left ventricle at rest and during exercise using echocardiography. Eur J Appl Physiol Occup Phys 1995; 70: 169-174.

26. Gledhill N, Cox D, Jamnik R. Endurance athletes stroke volume does not plateau: major advantage is diastolic function. Med Sci Sports Exerc 1994; 26: 1116-1121.

27. Casey DP, Joyner MJ. Compensatory vasodilatation during hypoxic exercise: mechanisms responsible for matching oxygen supply to demand. J Physiol 2012; 590: 6321-6326

28. Ogita F. Effects of intermittent hypobaric hypoxic exercise on cardiovascular adaptations. J Phys Fitness Sports Med 2013; 2: 341-345.

29. Wilkins BW, Pike TL, Martin EA, Curry TB, Ceridon ML, Joyner MJ. Exercise intensity-dependent contribution of beta-adrenergic receptor-mediated vasodilation. J Physiol 2008; 586: 1195-1205.

30. Casey DP, Madery BD, Curry TB, Eisenach JH, Wilkins BW, Joyner MJ. Nitric oxide contributes to the augmented vasodilatation during hypoxic exercise. J Physiol 2010; 588: 373-385.

31. Casey DP, Curry TB, Wilkins BW, Joyner MJ. Nitric oxide-mediated vasodilation becomes independent of Badrenergic receptor activation with increased intensity of hypoxic exercise. J Appl Physiool 2011; 110: 687-694.

32. Casey DP, Joyner MJ. Contribution of adenosine to compensatory dilation in hypoperfused contracting human muscles is independent of nitric oxide. J Appl Physiol 2011; 110: 1181-1189.

33. Crecelius AR, Kirby BS, Voyles WE, Dinenno FA. Augmented skeletal muscle hyperemia during hypoxic exercise in human is blunted by combined inhibition of nitric oxide and vasodilating protaglandins. J Physiol 2011; 589: 3671-3683.

34. Sheel AW, Macnutt MJ. Control of ventilation in humans following intermittent hypoxia. Appl Physiol Nutr Metab 2008; 33: 573-581.

35. Moreira TS, Takakura AC, Damasceno RS. Central chemoreceptors and neural mechanisms of cardiorespiratory control. Braz J Med Biol Res 2011; 44: 883-889.

\section{*Correspondence to}

Chaiyakul S

College of Sports Science and Technology

Mahidol University

Thailand 